\title{
Effect of social class at birth on risk and presentation of schizophrenia: case-control study
}

Fiona Mulvany, Eadbhard O’Callaghan, Noriyoshi Takei, Majella Byrne, Paul Fearon, Conall Larkin

Stanley Foundation
Research Unit,
Department of
Adult Psychiatry,
Hospitaller Order
of St John of God,
Cluain Mhuire
Family Centre,
Blackrock, Co
Dublin, Ireland
Fiona Mulvany
researcher
Majella Byrne
researcher
Conall Larkin
psychiatrist
Department of
Psychiatry,
University College,
Dublin
Eadbhard
O'Callaghan
professor
Department of
Psychiatry and
Neurology,
Hammamatsu
University School of
Medicine, 3600
Handa-cho,
Hammamatsu,
431-3192, Japan
Noriyoshi Takei
associate professor
Division of
Psychological
Medicine, Institute
of Psychiatry,
London SE5 8 AF
Paul Fearon
psychiatrist
Correspondence to:
E O'Callaghan,
Stanley Foundation
Research Unit,
Department of
Adult Psychiatry,
Hospitaller Order
of St John of God,
Cluain Mhuire
Family Centre,
Blackrock, Co
Dublin, Ireland
eadbhard@indigo.ie

BMJ 2001;323:1398-401

\begin{abstract}
Objectives To examine if low parental social class increases children's risk of subsequently developing schizophrenia or modifies the presentation.

Design Case-control study with historical controls. Setting Geographically defined region in south Dublin.

Participants 352 patients with first presentation of schizophrenia matched with the next registered same sex birth from the same birth registration district.

Main outcome measures Social class at birth. Age at presentation to psychiatric services, admission to hospital, and diagnosis of schizophrenia.

Results Risk of schizophrenia was not increased in people from lower social classes. There was a slight excess risk among people in highest social classes (odds ratio $0.59,95 \%$ confidence interval 0.40 to 0.85 ). However, the mean age at presentation was 24.8 years for patients whose parents were in the highest social class compared with 33.1 years for those in the lowest social class at birth.
\end{abstract}

Conclusions Although social class of origin does not seem to be an important risk factor for schizophrenia, it partially determines the age at which patients receive treatment. The relation between low social class at birth and poor outcome may be at least partially mediated through treatment delay.

\section{Introduction}

Psychiatric disorders have been consistently shown to be more common among people in lower social classes. $^{12}$ Schizophrenia is the mental illness most strongly linked to class, with working class people being about five times more likely to be diagnosed with schizophrenia than other groups. ${ }^{3}$

Many people who develop schizophrenia do not achieve or maintain the social class they were born into. By the time they have contact with psychiatric services, patients have often moved into a lower social class. ${ }^{45}$ However, this does not exclude the possibility that low social class increases the risk of later schizophrenia. ${ }^{6}$ Evidence is accumulating that the origins of the disorder lie in early life, and various environmental factors have been shown to be associated with an increased risk of later schizophrenia. ${ }^{8}$ These factors include obstetric complications, ${ }^{9}{ }^{10}$ prenatal infections, ${ }^{11}$ and nutritional deprivation, ${ }^{12}$ all of which are more common among people in lower social classes. ${ }^{13-15}$ However, it remains unclear whether people born into lower social classes are at increased risk of schizophrenia. ${ }^{16} 17$

Social class at birth could also modify the course of the disorder. There is often a considerable delay between the onset of psychotic symptoms and adequate treatment. People who have a longer duration of untreated psychosis have been shown to have a poorer outcome, ${ }^{18}{ }^{19}$ and social class influences the age at which people with other illnesses present to healthcare services. ${ }^{20}$ Using a case-control design, we investigated whether social class of origin influenced the risk of schizophrenia and the age at which patients first presented to psychiatric services for treatment.

\section{Participants and methods}

The sample was drawn from patients referred to Cluain Mhuire Family Centre, a geographically defined community based psychiatric service for a population of 165000 people. Cases were limited to patients who were subsequently admitted to Saint John of God Hospital for the first time with schizophrenia (diagnosis based on ICD-9, international classification of diseases, 9th edition). We selected a consecutive case series of patients $(n=629)$ discharged from their first admission to hospital between January 1984 and May 1993. We compiled clinical and demographic data for each patient within the catchment area from case notes and computerised records. We defined age at first contact with psychiatric service as any inpatient or outpatient contact with a mental health professional. The age at first diagnosis was defined as the date at which schizophrenia was diagnosed.

We searched the birth registration records of the 629 patients with the help of the General Register Office and recorded details of their father's occupation at the time of their birth. We were unable to locate the records for 140 patients, and a further 64 patients were excluded because they were not born in Ireland (19 people), they had an incorrect date of birth (4), details of fathers' occupation were not recorded (2), or their maiden name was missing (39 married women).

We recorded the paternal occupation of the next registered same sex birth from the birth registration district of the patient and used that child as a matched control. Paternal occupational data were compiled in accordance with the Census of Population Classification of Occupations, which consists of six categories (box). ${ }^{21}$ Farmers are assigned to a social class category on the basis of farm acreage, but this was not included on the birth registration record. We were therefore unable to assign social class categories to 31 cases and 51 controls. We were also unable to assign social class codes to fathers described on the birth certificate as unemployed (2 cases, 2 controls), student (1 case, 1 control), or pensioner (1 control). The final sample consisted of 391 cases and 370 controls, of which 352 were matched pairs.

\section{Power}

With 352 case-control pairs, this study had a power of $87 \%$ to detect a difference of $10 \%$ in the proportions of discordant pairs (classes I-III $v$ IV-VI) with respect to social class of origin provided that the proportion of discordant pairs was $37 \%$ at a two sided $5 \%$ significance level. We had sufficient patients in social classes I and VI to detect a difference between the two classes of 8.5 


\section{Social class scale ${ }^{21}$}

Social class $I$-Higher professional, higher managerial, proprietors, and farmers with $\geqslant 200$ acres $(81$ hectares)

Social class II-Lower professional, lower managerial, and farmers with 100-199 acres

Social class III-Other non-manual and farmers with 50-99 acres

Social class IV-Skilled manual and farmers with 30-49 acres

Social class $V$-Semiskilled manual and farmers with $<30$ acres

Social class VI-Unskilled manual

years in the age of first contact ( $80 \%$ power), 8.2 years in the age of first ever admission (78\% power), and 10 years in the age of first admission with schizophrenia (88\% power) at a two sided $1 \%$ significance level.

\section{Statistical analysis}

We investigated the distribution of social class backgrounds between cases and controls using the Wilcoxon matched pairs signed rank test. We then examined the proportions of discordant pairs for social class using McNemar's test, in which a binary social class variable (social class I-III $=$ high, social class $\mathrm{IV}$-VI = low) was created. In addition, we used a model of conditional logistic regression to fit the six social class categories as an explanatory variable. Next, we carried out analysis of variance to examine any difference in the age at first contact with psychiatric services, age at first ever admission, and age at first admission with a diagnosis of schizophrenia among the six social class groups. Finally, we fitted a regression model to quantify differences in ages at first use of the psychiatric services among the six social class of groups. Except for the conditional logistic regression analysis (STATA programme), we used the SPSS statistical package throughout.

\section{Results}

\section{Social class as risk factor for schizophrenia}

There was no overall significant difference between cases and controls in the distribution of social class (Wilcoxon rank sum $z=-1.3912, \mathrm{P}=0.16$ ). Within the 352 matched pairs, the patients and controls came from the same social class in 77 pairs; patients were from a higher social class in 149 pairs and from a lower social class in 126 pairs. The odds ratio of developing the disorder associated with social class (low $v$ high) was $0.59(95 \%$ confidence interval 0.40 to 0.85 , $\mathrm{P}<0.0029$ ), indicating that people from low social classes have a reduced risk of schizophrenia compared with those from high social classes.

Table 1 shows that the risk of developing schizophrenia varies across the six social classes of origin. There was no consistent trend in odds ratios across the social classes, although people in lower classes tended to have a lower risk than those in higher classes. However, the likelihood ratio statistic from conditional logistic regression was $11.39(\mathrm{df}=5, \mathrm{P}=0.044)$, indicating a significant overall difference in risk across social classes.

\section{Relation between social class and age at first} presentation

There was an overall significant difference in the age at first contact among the six social classes $(F=2.95$, $\mathrm{df}=5,345 ; \mathrm{P}=0.01)$. The mean age at first contact with psychiatric services was 30.1 years in the whole sample (men 28.6 years; women 32.2 years). Patients in social class I were youngest at first contact (25.3 years) and those in social class VI the oldest (34.4 years). Similarly, there was an overall significant difference in the age at first ever admission $(F=2.55, \mathrm{df}=5,345 ; \mathrm{P}=0.03)$. The mean age at first ever admission to a psychiatric hospital was 29.6 years (men 28.2 years; women 31.6 years). Patients in social class I were youngest at first ever admission (24.8 years) and those in social class VI oldest (33.1 years). We also found a significant difference in the age at first admission with schizophrenia $(F=3.92, \mathrm{df}=5,345 ; \mathrm{P}=0.002)$; the mean age at first admission with schizophrenia was 33.3 years (men 31.4 years; women 36.0 years), with patients in social class I being the youngest (28.0 years) and those in social class VI the oldest (38.8 years).

We found no evidence that sex modified the effect in any of the above measures $(F=1.22, \mathrm{df}=5,340$; $\mathrm{P}=0.30$ for age at first contact; $F=1.51, \mathrm{df}=5,340$; $\mathrm{P}=0.19$ for age at first admission; and $F=1.84, \mathrm{df}=5$, $340 ; \mathrm{P}=0.10$ for age at first admission with schizophrenia), which indicates that age differences between the two sexes are identical across social classes. Sex distribution did not differ significantly across the social classes $\left(\chi^{2}=7.50, \mathrm{df}=5, \mathrm{P}=0.19\right)$. Thus, sex is unlikely to confound the results. Nevertheless, we controlled for sex in the estimates of differences in age of contact, admission, and diagnosis between patients from different social classes.

Table 2 shows that men tended to be younger than women from the same social class background at time of first contact with psychiatric services, first admission, and diagnosis of schizophrenia. Analysis of variance showed a significant main effect of sex for age at first contact $(F=5.87, \mathrm{df}=1,345 ; \mathrm{P}=0.016)$, age at first ever admission $(F=5.41, \mathrm{df}=1,345 ; \mathrm{P}=0.021)$, and age at first admission with schizophrenia $(F=9.30, \mathrm{df}=1$, $345 ; \mathrm{P}=0.002$ )

\section{Discussion}

We found no link between social class at birth and risk of schizophrenia. However, people in lower social classes tended to present later than those in higher social classes. Men also presented at a younger age than women in the same social class.

\section{Validity of data}

We located $68 \%$ of the birth registration records and had matched pair data for $56 \%$ of records. This is a

Table 1 Risk of developing schizophrenia according to social class at birth

\begin{tabular}{lcc} 
Social class & Odds ratio & 95\% Cl \\
\hline I & & 1 \\
\hline II & 0.93 & 0.52 to 1.68 \\
\hline $\mathrm{III}$ & 0.99 & 0.66 to 1.75 \\
\hline $\mathrm{IV}$ & 0.50 & 0.28 to $0.90^{*}$ \\
\hline $\mathrm{V}$ & 0.52 & 0.27 to 1.02 \\
\hline $\mathrm{VI}$ & 0.70 & 0.38 to 1.31 \\
\hline${ }^{*} \mathrm{P}<0.05$. &
\end{tabular}


Table 2 Age at first contact with psychiatric services, first admission, and first diagnosis of schizophrenia by social class

\begin{tabular}{lcccc} 
Social class & No & $\begin{array}{c}\text { Mean (SD) age at } \\
\text { first contact (years) }\end{array}$ & $\begin{array}{c}\text { Mean(SD) age at first } \\
\text { admission (years) }\end{array}$ & $\begin{array}{c}\text { Mean (SD) age at first } \\
\text { admission with } \\
\text { schizophrenia (years) }\end{array}$ \\
\hline All & 352 & $30.1(13.1)$ & $29.6(12.8)$ & $33.3(13.9)$ \\
\hline Men & 205 & $28.6(12.0)$ & $28.2(11.6)$ & $31.4(12.2)$ \\
\hline Women & 147 & $32.2(14.4)$ & $31.6(14.0)$ & $36.0(15.6)$ \\
\hline Men & 48 & $25.3(9.1)$ & $24.8(8.2)$ & $28.0(8.7)$ \\
\hline Women & 31 & $24.4(6.1)$ & $24.0(6.0)$ & $26.6(6.0)$ \\
\hline I & 17 & $27.1(13.0)$ & $26.4(11.3)$ & $30.4(11.9)$ \\
\hline Men & 60 & $31.1(12.7)$ & $31.0(12.3)$ & $34.1(13.6)$ \\
\hline Women & 26 & $30.3(11.4)$ & $30.2(11.3)$ & $32.0(11.9)$ \\
\hline III & 34 & $31.7(13.7)$ & $31.7(13.2)$ & $35.7(14.8)$ \\
\hline Men & 68 & $29.8(13.9)$ & $29.3(13.1)$ & $33.0(14.3)$ \\
\hline Women & 44 & $29.8(14.0)$ & $29.4(13.7)$ & $33.4(15.1)$ \\
\hline IV & 24 & $29.9(14.1)$ & $29.0(12.3)$ & $32.0(13.3)$ \\
\hline Men & 68 & $29.1(12.3)$ & $29.2(12.5)$ & $30.7(10.5)$ \\
\hline Women & 40 & $27.7(10.3)$ & $28.0(10.6)$ & $33.9(16.5)$ \\
\hline V & 28 & $31.0(14.8)$ & $30.9(14.9)$ & $31.9(14.6)$ \\
\hline Men & 39 & $28.8(14.0)$ & $28.4(13.6)$ & $31.8(16.5)$ \\
\hline Women & 23 & $28.3(16.2)$ & $28.2(15.5)$ & $32.1(11.9)$ \\
\hline VI & 16 & $29.6(10.5)$ & $28.6(10.8)$ & $38.8(15.3)$ \\
\hline Men & 69 & $34.4(14.4)$ & $33.1(14.4)$ & $33.6(12.4)$ \\
\hline Women & 41 & $30.3(12.0)$ & $28.9(11.1)$ & $46.5(16.0)$ \\
\hline & 28 & $40.4(15.6)$ & $39.3(16.5)$ & \\
\hline
\end{tabular}

similar proportion to that identified by Goldberg and Morrison (55\%), but lower than that in the study by Hare and colleagues (75\%), both of which used similar methods. ${ }^{17}$ If the rate of mandatory birth registration of people from lower social groups were lower than that from higher social groups, the study would have systematic bias. We could find no evidence to support systematic bias, but an undetected bias would greatly affect our conclusions.

The strengths of this study lie in the relatively low geographical mobility of the population and the strict geographically defined catchment area for delivery of psychiatric services. Furthermore, the relative ethnic homogeneity of the study population avoided some potential cultural confounders. Not all patients were born in the catchment area, so we did not restrict the study to those whose parents were born and living within the index area. We identified the controls on a case by case basis from the district in which the patients' parents were living at the time of birth. We used temporally matched data because social class profiles have been shown to differ across decades and within countries. ${ }^{22}$

\section{What is already known on this topic}

Schizophrenia is more common in people from lower social classes

This could be due to increased vulnerability or social drift

\section{What this study adds}

Low social class at birth was not associated with increased risk of schizophrenia

People from lower social classes were older at first contact with psychiatric services than those from higher social classes

Delay in treatment of psychosis may explain the adverse outcome among people in low social classes
We used general population rather than psychiatric controls but we have no information on the outcome of the controls. Although it is possible that some developed schizophrenia, because the lifetime risk is $1 \%$ no more than four of the 352 controls are likely to have developed the disorder.

We had to rely on ICD-9 criteria for the diagnosis of schizophrenia rather than Diagnostic and Statistical Manual of Mental Disorders (DSM-IV) criteria, which are more restrictive and would have given a lower rate of schizophrenia. A recent report suggests that rigid adherence to DSM-IV criteria may lead to underdiagnosis of schizophrenia. $^{23}$ Furthermore, unless using the ICD criteria led to non-random misclassification, it will, at most, lessen the true strength of the association. Our data relate only to people who were admitted to hospital. However, during the study period over $98 \%$ of patients diagnosed with schizophrenia were admitted as inpatients.

\section{Comparison with other studies}

Our data contrast with the findings of Croudace and colleagues, who reported an increased risk of schizophrenia among people from lower social classes. ${ }^{7}$ A study of a northern Finland 1966 birth cohort, in which 11017 people alive at the age of 16 years were followed up, found similar results to ours. ${ }^{24}$ The two studies are not directly comparable, however, because our case-control study is sensitive to systematic bias and their cohort study did not follow up participants beyond age 27 years.

The cumulative incidence of early onset schizophrenia was higher among young people in the highest social class (according to father's occupation) than among young people in lower social classes. Therefore, the consistently observed excess of patients in the lowest social class is probably accounted for by people with schizophrenia moving into lower social classes or not moving out of lower social classes. ${ }^{25}$

\section{Effect of age on presentation}

We found more than an eight year difference in age at first presentation to psychiatric services between the lowest and highest social classes. Although it is possible that schizophrenia has a different age at onset across social classes, this is unlikely. Similarly, it is unlikely that family doctors are selectively not referring patients from lower social classes. Use of health services differs between the social classes. For example, people in the lowest social class are least likely to seek early antenatal care; middle class parents are more likely to seek medical attention for their children; and working class adults are likely to be more ill than are middle class adults before seeking help. ${ }^{20}$ Schizophrenia is probably subject to the same social class effects.

One explanation for the effect of social class is that people from lower social classes find it more difficult to access services. ${ }^{22}$ However, Cooper found no support for this hypothesis, ${ }^{26}$ and in our region the community service is more focused on people from lower socioeconomic groups. Furthermore, once patients present to the psychiatric service there is little if any social class gradient in time to first diagnosis. Alternatively, people from the higher social classes may be better informed about schizophrenia or find it easier to identify deviations from the expected social and academic or occupational functioning. ${ }^{27}{ }^{28}$ Other 
studies suggest that the beliefs and values of people in lower socioeconomic groups, such as their tolerance and acceptance of the behavioural and social aspects of the disorder ${ }^{18}$ and their sense of low control or powerlessness, ${ }^{29}$ may help to explain the observed socioeconomic inequalities.

A "contact" study found that low social class at birth increased the duration of untreated psychosis. ${ }^{30}$ If, as we suspect, people with schizophrenia from lower social classes are not presenting to family doctors, those with the least financial resources and opportunities for employment may be the most exposed to the adverse effects of untreated psychosis. This delay may, at least partially, explain why people from lower social class have a less favourable outcome. ${ }^{13}$ Efforts to reduce the duration of untreated psychosis through earlier detection should be particularly focused on people in lower social classes. In addition, researchers should be careful to adjust for social class at birth if using age at first presentation as a measure of age at onset of schizophrenia.

We thank the St John of God Order and the Stanley Foundation for their support and staff of the General Register Office, Dublin, for help in locating birth registration records.

Contributors: EOC and FM initiated and designed the study in collaboration with MB and NT. FM, NT, and PF did the statistical analyses. FM and MB collected and validated the data. FM, EOC, NT, and CL wrote the first draft of the paper and all authors participated in the interpretation of the results and editing the paper. EOC is the guarantor.

Funding: Stanley Foundation and Hospitaller Order of St John of God.

Competing interests: None declared.

1 Goldberg EM, Morrison SL. Schizophrenia and social class. Br J Psychiatry 1963;109:785-809.

2 Wiersma D, Giel R, De Jong A, Slooff CJ. Social class and schizophrenia in a Dutch cohort. Psychol Med 1983;13:141-50.

3 Argyle M. The psychology of social class. London: Routledge, 1994.

4 Jones PB, Bebbington P, Foerster A, Lewis SW, Murray RM, Russell A, et al. Premorbid social underachievement in schizophrenia. Br J Psychiatry 1993;162:65-71.

5 Aro S, Aro H, Keskimäki I. Socioeconomic mobility among patients with schizophrenia or major affective disorder. A 17 -year retrospective followup. BrJ Psychiatry 1995;166:759-67.

6 Warner R, de Girolamo G. Schizophrenia. Geneva: World Health Organization, 1995 .

7 Croudace TJ, Kayne R, Jones PB, Harrison GL. Non-linear relationship between an index of social deprivation, psychiatric admission prevalence and the incidence of psychosis. Psychol Med 2000;30:177-85.
8 Murray RM, Lewis SW. Is schizophrenia a neurodevelopmental disorder? BMJ 1987;295:681-2.

9 Geddes JR, Lawrie SM. Obstetric complications and schizophrenia: a meta-analysis. Br J Psychiatry 1995;167:786-93.

10 Hultman CM, Sparén P, Takei N, Murray RM, Cnattingius S, Geddes J. Prenatal and perinatal risk factors for schizophrenia, affective psychosis, and reactive psychosis of early onset: case-control study. BMJ and reactive psyct

11 Sham PC, O'Callaghan E, Takei N. Schizophrenia following pre-natal exposure to influenza epidemics between 1939 and 1960. Br J Psychiatry 1992;160:461-6.

12 Susser ES, Lin SP. Schizophrenia after prenatal exposure to the Dutch hunger winter of 1944-1945. Arch Gen Psychiatry 1992;49:983-8.

13 Saugstad LF. Social class, marriage and fertility in schizophrenia. Schizophr Bull 1989;15:9-44.

14 Wynn SW, Wynn AH, Doyle W. The association of maternal social clas with maternal diet and the dimensions of babies in a population of London women. Nutr Health 1994;9:303-15.

15 Saxena S, Majeed A, Jones M. Socioeconomic differences in childhood consultation rates in general practice in England and Wales: prospective cohort study $B M J$ 1999:318:642-6

16 Turner RJ, Wagenfeld MO. Occupational mobility and schizophrenia: an assessment of social causation and social selection hypothesis. Am Sociol Rev 1967;32:104-13.

17 Hare EH, Price JS, Slater E. Parental social class in psychiatric patients. $B r$ J Psychiatry 1972;121:515-24.

18 Loebel AD, Lieberman JA, Alvir JMJ, Mayerhoff DI, Geisler SH, Szymanski SR. Duration of psychosis and outcome in first-episode schizophrenia. Am J Psychiatry 1992;149:1183-8.

19 Carbone S, Harrigan S, McGorry PD. Duration of untreated psychosi and 12 month outcome in first episode psychosis: the impact of treatment approach. Acta Psychiatr Scand 1999;100:96-104.

20 Department of Health and Social Security. Inequalities in health: report of a research working group. London: DHSS, 1980.

21 Central Statistics Office. Census of Population 1986 Classification of Occupa tions. Dublin: Stationery Office, 1986.

22 Birtchnell J. Social class, parental social class and social mobility in psychiatric patients and general population controls. Psychol Med 1971;1:209-21.

23 Schwartz JE, Fennig S, Tanenberg-Karant M, Carlson G, Craig T, Galambos N, et al. Congruence of diagnoses 2 years after a first-admission diagnosis of psychosis. Arch Gen Psychiatry 2000;57:593-600.

24 Mäkikyrö T, Isohanni $\mathrm{M}$, Moring J. Is a child's risk of early onset schizophrenia increased in the highest social class? Schizophr Re 1997;23:245-52.

25 Dohrenwend BP, Levav I, Shrout PE, Schwartz S, Naveh G, Link BG, et al Socioeconomic status and psychiatric disorders: the causation-selection issue. Science 1992;255:946-52.

26 Cooper B. Social class and prognosis in schizophrenia. Br J Prev Soc Med 1961;15:17-41.

27 Roberts K. School, parents and social class. In: Craft M, Raynor J, Cohen $\mathrm{L}$, eds. Linking home and school. A new review. 3rd ed. London: Harper and Row, 1980.

28 Horwitz AV. Help-seeking processes and mental health services. New Dir Ment Health Serv 1987;36:33-45.

29 Bosma H, Schrijvers C, Mackenbach JP. Socioeconomic inequalities in mortality and importance of perceived control: cohort study. BMJ 1999,319:1469-70.

30 Clarke M, Brown S, McTigue O, Gervin M, Murphy P, Waddington JL, et al. Duration of untreated psychosis in first episode schizophrenia and its relationship to premorbid functioning. Schizophr Res 1999;36:38-9.

(Accepted 13 September 2001)

\title{
The impact of new drugs on management of glaucoma in Scotland: observational study
}

\author{
D N Bateman, R Clark, A Azuara-Blanco, M Bain, J Forrest
}

Glaucoma is one of the most common causes of blindness worldwide (it is exceeded only by cataracts), and it accounts for $12 \%$ of cases of registered blindness in the United Kingdom. ${ }^{1}$ The vast majority of patients with glaucoma do not become functionally blind, but the pronounced visual loss these patients have, and its effects on function, are not considered by current statistics. Most cases are due to primary opening angle glaucoma, the prevalence of which increases in elderly people and is well established. ${ }^{2}$

There are two main treatment approaches for glaucoma-medical and surgical. Trabeculectomy is the standard surgical procedure. Twenty years ago, topical $\beta$ blockers revolutionised the medical management of glaucoma, but in the early 1990s researchers advocated early operative intervention for glaucoma." Over the past five years, three new classes of drugs for this condition have been introduced-prostaglandin analogues (latanoprost), topical carbonic anhydrase inhibitors (such as dorzolamide), and $\alpha-2$ agonists (brimonidine). Patients with glaucoma are managed almost exclusively by ophthalmic services. ${ }^{4}$ We examined the impact of new treatments for glaucoma by examining prescribing and operating statistics for
National Poisons Information Service (Edinburgh), Scottish Poisons Information Bureau, Royal Infirmary of Edinburgh, Edinburgh EH3 9YW D N Bateman director

continued over

BMJ 2001;323:1401-2 